\title{
Controllability study of an ethanol steam reforming process for
}

\section{hydrogen production}

\author{
Vanesa M. García $^{a *}$, Maria Serra ${ }^{\text {a }}$, Jordi Llorca ${ }^{b}$ \\ ${ }^{a}$ Institut de Robòtica i Informàtica Industrial (CSIC-UPC). Llorens i Artigas 4-6, 08028 \\ Barcelona, Spain. \\ ${ }^{\mathrm{b}}$ Institut de Tècniques Energètiques. Universitat Politècnica de Catalunya (UPC). \\ Diagonal 647, ed. ETSEIB. 08028 Barcelona, Spain.
}

\begin{abstract}
A system for ethanol steam reforming and purification of carbon monoxide (CO) designed to feed a PEM fuel cell has been modelled. From the model, we study the sensitivity and controllability emphasizing the study of the influence of the temperature on the output variables of interest. The results of the study of controllability are used for the identification of the best control structures.
\end{abstract}

Keywords: Steam reforming, Hydrogen production, Controllability, Control structures, MIMO system, PEMFC.

* Corresponding author:

Vanesa M. García

Institut de Robòtica i Informàtica Industrial (CSIC-UPC)

Llorens i Artigas 4-6, 08028 Barcelona, Spain

Tel.: (+34) 934015805

Fax.: (+34) 934015750

e-mail:vgarcia@iri.upc.edu 


\section{Introduction}

The gradual reduction of fossil fuel reserves and the environmental pollution problems associated with their combustion have turned the attention of researchers to the search for alternative energy carriers. The energy vector that is currently receiving more attention is hydrogen, considered as a possible candidate to partially replace oil as fuel in mobile applications. However, hydrogen can only be considered a clean alternative if it comes from clean energy sources. Ethanol can be considered a source of $\mathrm{H}_{2}$ neutral in relation to $\mathrm{CO}_{2}$ emissions. This has motivated many investigations focusing on the design of reactors for the production of $\mathrm{H}_{2}$, but less attention has been given to the control of the developed systems, that includes tasks such as the selection of the control structures and the design and tuning of the controllers. There exist different tools for the task of selecting the controlled, manipulated and measured variables and link these variables to make control loops [2]. The main mathematical methods for designing control structures are based on the relative gains [2] and singular value decomposition analysis [1][2]. In this work we select the most appropriate control structures for an ethanol reformer

Reforming Process

- Ethanol dehydrogenation to acetaldehyde and hydrogen (EtOHD)

- Acetaldehyde Reforming (AcR)

- Water Gas Shift reaction (WGS)

Purification Unit

- Condenser (CON)

- Preferential Oxidation of CO (CO-PrOx)

\section{Description of the ethanol steam reforming process and the dynamic model}


In previous publications, we have described a non-linear dynamic model for a lowtemperature ethanol steam reformer based on a cobalt catalyst [5]. It consists in a tubular reactor loaded with catalytic monoliths. The reforming process is divided in three separated stages (EtOHD, AcR and WGS). Experimental data for the kinetics of the two first stages was given in [3]. In this work, we have considered in addition a purification unit, which is required to directly provide hydrogen from the reactor to a fuel cell.

\subsection{Description of the ethanol steam reforming process}

\subsubsection{Reforming unit}

In the first stage, ethanol reacts over $\mathrm{SnO}_{2}$ to produce acetaldehyde and hydrogen according to the reaction:

$$
\mathrm{C}_{2} \mathrm{H}_{5} \mathrm{OH} \rightarrow \mathrm{C}_{2} \mathrm{H}_{4} \mathrm{O}+\mathrm{H}_{2}
$$

The order of the reaction was established in [3] by changing the ethanol load at a series of temperatures between 573 and $673 \mathrm{~K}$. A first-order reaction was identified and a kinetic law provided.

The acetaldehyde-steam mixture is transformed over $\mathrm{Co}(\mathrm{Fe}) / \mathrm{ZnO}$ catalyst in the second stage into a mixture of hydrogen, carbon monoxide, and carbon dioxide, according to the reactions:

$$
\begin{aligned}
& \mathrm{C}_{2} \mathrm{H}_{4} \mathrm{O}+\mathrm{H}_{2} \mathrm{O} \rightarrow 3 \mathrm{H}_{2}+2 \mathrm{CO} \\
& \mathrm{C}_{2} \mathrm{H}_{4} \mathrm{O}+\mathrm{H}_{2} \mathrm{O} \rightarrow 5 \mathrm{H}_{2}+2 \mathrm{CO}_{2} \\
& \mathrm{CO}+\mathrm{H}_{2} \mathrm{O} \rightarrow \mathrm{CO}_{2}+\mathrm{H}_{2}
\end{aligned}
$$

For the kinetics of reations (2) and (3) a dependency on only acethaldehyde concentration was encountered [3]. The kinetics of the reaction (4) is based on the 
partial pressures of all the components involved in the reaction. The velocity rates of these reactions are:

$$
\begin{aligned}
& \mathrm{r}_{\mathrm{C} 2 \mathrm{H} 4 \mathrm{O}}=\mathrm{k}_{1,2} \quad \mathrm{e}^{\frac{\mathrm{Ea}, \mathrm{C2} H 4 \mathrm{O}}{\mathrm{R}_{\mathrm{T}}}} \quad \mathrm{C}_{\mathrm{C} 2 \mathrm{H} 4 \mathrm{O}} \\
& \mathrm{r}_{\mathrm{CO}, \mathrm{S} 2}=\mathrm{k}_{3} \quad \mathrm{e}_{\mathrm{R} \mathrm{T}}^{\mathrm{Ea} a \mathrm{O}} \quad \mathrm{p}_{\mathrm{CO}} \quad \mathrm{p}_{\mathrm{H}_{2} \mathrm{O}} \quad\left(1-\frac{1}{\mathrm{~K}_{\mathrm{eq} 3}} \frac{\mathrm{p}_{\mathrm{CO}_{2}} \mathrm{p}_{\mathrm{H}_{2}}}{\mathrm{p}_{\mathrm{CO}} \mathrm{p}_{\mathrm{H}_{2} \mathrm{O}}}\right)
\end{aligned}
$$

The values of the reaction constans $\left(\mathrm{k}_{1}-\mathrm{k}_{3}\right)$ are $1.38 \times 10^{4} \mathrm{mLg}_{\mathrm{cat}}{ }^{-1} \mathrm{~h}^{-1}, 1.52 \times 10^{4}$ $\mathrm{mLg}_{\text {cat }}{ }^{-1} \mathrm{~h}^{-1}$ and $9.2 \times 10^{2} \mathrm{~mol} \mathrm{~m}^{-3} \mathrm{~s}^{-1} \mathrm{~atm}^{-2}$, respectively. The activation energies

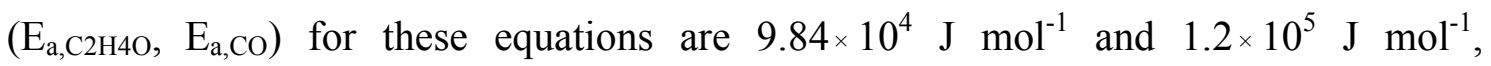
respectively [3].

In the third stage, a $\mathrm{Fe}_{2} \mathrm{O}_{3}-\mathrm{Cr}_{2} \mathrm{O}_{3}$ catalyst has been used to further carry out the WGS for decreasing the $\mathrm{CO}$ content in the reformate. In this case, the experimental data are taken from [4]. This work has been chosen because it is based on operating conditions (rank of temperatures and pressure) similar to the conditions of our system. In this case, the Langmuir-Hinshelwood (L-H) model (7) describes adequately the reaction behavior over the temperature and concentration ranges investigated [4].

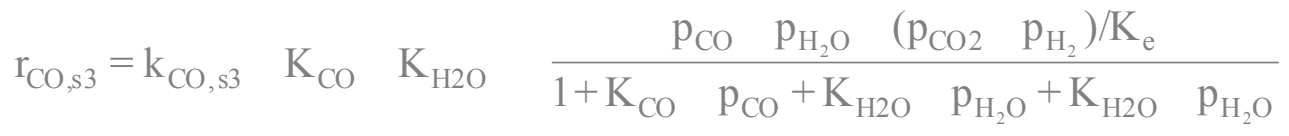

\subsubsection{Purification unit}

The purification unit has been specifically included in this work and comprises a condenser and a $\mathrm{CO}$ preferential oxidation $(\mathrm{CO}-\mathrm{PrOx})$ reactor based on a $\mathrm{Pt}$ catalyst [7]. The condenser is used to cool hot vapors at the output of the third stage and separate hydrogen and carbon oxides from excess water and unreacted ethanol and acetaldehyde, whereas the purpose of the $\mathrm{PrOx}$ reactor is to reduce the concentration of $\mathrm{CO}$ at the inlet 
of the fuel cell stack. In the PrOx reactor, air is mixed with the feed stream to preferentially oxidize $\mathrm{CO}(8)$ while minimizing the consumption of $\mathrm{H}_{2}(9)$ :

$$
\begin{aligned}
& \mathrm{CO}+\frac{1}{2} \mathrm{O}_{2} \rightarrow \mathrm{CO}_{2} \\
& \mathrm{H}_{2}+\frac{1}{2} \mathrm{O}_{2} \rightarrow \mathrm{H}_{2} \mathrm{O}
\end{aligned}
$$

As indicated in [7], the reaction rates in the CO-PrOx stage are described by:

$$
\begin{aligned}
& \mathrm{r}_{\mathrm{CO}}=\frac{2 \mathrm{k}_{\mathrm{O}_{2}} \mathrm{x}_{\mathrm{O}_{2}}}{\sqrt{\mathrm{x}_{\mathrm{O}_{2}}}+\mathrm{k}_{\mathrm{CO} \sqrt{\mathrm{x}_{2}}}} \\
& \mathrm{r}_{2}=\frac{\sqrt{\mathrm{x}_{\mathrm{H}_{2}}}}{\mathrm{k}_{\mathrm{CO}} \sqrt{\mathrm{x}_{\mathrm{CO}}}} \frac{2 \mathrm{k}_{\mathrm{O}_{2}} \mathrm{x}_{\mathrm{O}_{2}}}{\sqrt{\mathrm{x}_{\mathrm{H}_{2}}}+\mathrm{k}_{\mathrm{CO}} \sqrt{\mathrm{x}}} \\
& 2 \mathrm{r}_{\mathrm{O}_{2}}=\mathrm{r}_{\mathrm{CO}}+\mathrm{r}_{\mathrm{H}_{2}}
\end{aligned}
$$

where

$$
\begin{aligned}
& \mathrm{k}_{\mathrm{O}_{2}}=8.9 \times 10^{6} \mathrm{e}^{10700 /\left(\mathrm{RT}_{\mathrm{S}}\right)} \sqrt{\frac{\mathrm{P}}{1.7}} \\
& \mathrm{k}_{\mathrm{CO}=} 13.7
\end{aligned}
$$

To simulate the condenser, we have solved a system of non-linear equations with $\operatorname{MATLAB}^{\mathrm{TM}}$.

\subsection{Dynamic model}

To obtain the dynamic model of the system, pressure is considered constant at one atmosphere and the volumetric velocity variation along the reactor is taken into account. In the purification unit, isothermal conditions are assumed. Radial variations are neglected and only the axial profiles are considered. 
The mathematical model is based on the mass balance and the energy balance, and it is assumed that the reactor is a pseudohomogeneous system by considering that the gas temperature and the solid temperature are the same [8].

Mass balance (for component $\mathrm{j}$ ):

$$
\frac{\partial \mathrm{C}_{\mathrm{j}}}{\partial t}+\frac{\partial\left(\mathrm{vC}_{\mathrm{j}}\right)}{\partial \mathrm{z}}=v_{\mathrm{j}, \mathrm{i}} \mathrm{r}_{\mathrm{i}}
$$

Energy balance:

$\left[\rho_{\text {gas }} c_{p_{\text {gas }}}+\rho_{\mathrm{s}} c_{p_{s}}\right] \frac{\partial T}{\partial t}+\rho_{g} c_{p_{\text {gas }}} v \frac{\partial T}{\partial z}=\frac{4 U}{d_{t}}\left(T_{F}-T\right)+\left(-\Delta H_{i}\right) r_{i}$

The energy balance parameters [9] are $\mathrm{U}=4000\left[\mathrm{~J} \cdot \mathrm{s}^{-1} \mathrm{~K}^{-1} \mathrm{~m}^{-3}\right], \rho_{\mathrm{s}}=500\left[\mathrm{~kg} \cdot \mathrm{m}^{-3}\right]$ and the density of the gas has been obtained from the following equation:

$$
\delta_{\text {gas }}=\frac{\mathrm{P} \mathrm{M}_{\mathrm{mi}}}{\mathrm{R} \mathrm{T}_{\mathrm{gas}, \mathrm{si}}}
$$

To simulate the dynamic behaviour, initial conditions and boundary conditions are set as:

Initial conditions

$$
\begin{aligned}
& C_{j}(0, x)=C_{j 0}(x) \quad \text { with } \quad x \in[1, L], j=1,2, \ldots N \\
& T_{j}(0, x)=T_{j 0}(x) \quad \text { with } \quad x \in[1, L], j=1,2, \ldots N
\end{aligned}
$$

Boundary conditions

$$
\begin{aligned}
\mathrm{C}_{\mathrm{j}}(\mathrm{t}, 0) & =\mathrm{C}_{\mathrm{je}}(\mathrm{t}) \text { with } \mathrm{t}>0 \\
\mathrm{~T}_{\mathrm{j}}(\mathrm{t}, 0) & =\mathrm{T}_{\mathrm{je}}(\mathrm{t}) \text { with } \mathrm{t}>0
\end{aligned}
$$

The numerical solution of the partial differential equations (15) and (16) was accomplished by its transformation into an ODE-system by discretization of the spatial derivative. To this end, backward finite differences have been selected (first-order, 15 discretization points for the reported simulations) for the different stages of the reforming unit. The resulting 285 ODE equations were solved by an algorithm 
implemented in MATLAB ${ }^{\mathrm{TM}}$ (ODE45 Normand-Prince). Additional details regarding the mathematical model can be found in [5].

\subsection{The linear model}

A linearized model was obtained from the non-linear model of the system using SIMULINK ${ }^{\star}$ linearization tools, as reported in [3]. The state space representation of the system has a very large dimension and therefore, a model reduction strategy has been applied to transform the original model into a simplified form that has lower order and preserves the dynamic characteristics of the original high-order system [5]. The linear model is the base of the controllability study developed in this work. In addition, the comparison between the non-linear and the linear models will provide information about the suitability of selecting linear controllers. In this work, the goal is to perform a sensitivity and controllability analysis of the reforming process emphasizing the influence of the temperature variables. We have considered as inputs the flowrates of ethanol and water at the reactor entrance $\left(\mathrm{F}_{\mathrm{C} 2 \mathrm{H} 5 \mathrm{OH}}, \mathrm{F}_{\mathrm{H} 2 \mathrm{O}}\right)$, the temperature of the entering mixture $\left(T_{g, i n}\right)$, and the temperatures of the furnaces of the three reforming stages $\left(T_{f, S 1}\right.$, $\mathrm{T}_{\mathrm{f}, \mathrm{S} 2}, \mathrm{~T}_{\mathrm{f}, \mathrm{S} 3}$ ). As outputs (control objectives), we have selected the flowrates of $\mathrm{H}_{2}$ and $\mathrm{CO}\left(\mathrm{F}_{\mathrm{H} 2}\right.$ and $\left.\mathrm{F}_{\mathrm{CO}}\right)$ at the output of the reformer.

Figure 1 shows the multiple inputs (manipulated variables) and multiple outputs (control variables) of the MIMO system.

The linear model in state space has the form:

$$
\begin{aligned}
& x=A x+B_{u} u \\
& z=C x+D_{u} u
\end{aligned}
$$


where the state $x$ contains the concentrations of all components in the different volumes what the reactor has been divided. The input vector $u$ contains the manipulated variables and the output vector $z$ contains the controlled variables.

$\mathrm{z}=\left[\mathrm{F}_{\mathrm{H} 2}, \mathrm{~F}_{\mathrm{CO}}\right]$

$\mathrm{u}=\left[\mathrm{F}_{\mathrm{C} 2 \mathrm{H} 5 \mathrm{OH}} \mathrm{F}_{\mathrm{H} 2 \mathrm{O}} \mathrm{T}_{\mathrm{g}, \text { in }} \mathrm{T}_{\mathrm{f}, \mathrm{S} 1} \mathrm{~T}_{\mathrm{f}, \mathrm{S} 2} \mathrm{~T}_{\mathrm{f}, \mathrm{S} 3}\right]^{\mathrm{T}}$

\subsection{Linear and non-linear models comparison}

In this study, the nominal steady-state is selected at a $\mathrm{H}_{2}$ yield value of $\eta^{\mathrm{H} 2}=80 \%$ and a molar fraction of carbon monoxide of $\mathrm{y}_{\mathrm{CO}}=0.83 \%$ (see Table 3), which is suitable for entering the CO-PrOx reactor. The non-linear model is evaluated at four different operating points that correspond to the following variations with respect to the nominal operating point:

- $\mathrm{OP}_{1}\left(\Delta \mathrm{F}_{\mathrm{C} 2 \mathrm{H} 5 \mathrm{OH}}\right): 10 \%$ ethanol input increase while the other five inputs are kept at the nominal values

- $\mathrm{OP}_{2}\left(\Delta \mathrm{F}_{\mathrm{H} 2 \mathrm{O}}\right): 10 \%$ water input increase while the other five inputs are kept at the nominal values

- $\mathrm{OP}_{3}\left(\Delta \mathrm{T}_{\mathrm{g}, \mathrm{in}}\right): 10 \%$ gas temperature input increase while the other five inputs are kept at the nominal values

- $\mathrm{OP}_{4}\left(\Delta \mathrm{T}_{\mathrm{f}, \mathrm{S} 2}\right): 5 \%$ furnace temperature of stage 2 input increase while the other five inputs are kept at the nominal values

The response of $\mathrm{F}_{\mathrm{H} 2}$ following step changes in the different inputs are shown in Figure 2, where both, the linear and the non-linear model results have been plotted. It can be observed that the linear model curves have minimal differences with respect to the non-linear model curves in the case of changes in $\mathrm{F}_{\mathrm{C} 2 \mathrm{H} 5 \mathrm{OH}}, \mathrm{F}_{\mathrm{H} 2 \mathrm{O}}$, and $\mathrm{T}_{\text {g,in. }}$. On the 
contrary, the difference is notable when there is a change in $\mathrm{T}_{\mathrm{f}, \mathrm{S} 2}$. This non-linearity can complicate the control of the system if $\mathrm{T}_{\mathrm{f}, \mathrm{S} 2}$ is used as a manipulated variable to control $\mathrm{F}_{\mathrm{H} 2}$.

Figure 3 shows the $\mathrm{F}_{\mathrm{CO}}$ output response. The differences between the linear and nonlinear models are small for step changes in the four considered inputs. The influence of $\mathrm{T}_{\mathrm{f}, \mathrm{S} 1}$ and $\mathrm{T}_{\mathrm{f}, \mathrm{S} 3}$ is not shown but has also been evaluated, and it has been seen that these temperatures cause more linear responses than $\mathrm{T}_{\mathrm{f}, \mathrm{S} 2}$. Therefore, from this comparison of the linear and the non-linear models, it can be concluded that, although it will be important to take care of the influence of $\mathrm{T}_{\mathrm{f}, \mathrm{S} 2}$, the linear model can be considered a valid control analysis tool. The offsets between the linear model and the non-linear model profiles, are indicated numerically in Table 1.

\subsection{Time evolution of the output variables due to input changes}

The time evolution of the reforming process variables is critical because the fuel processor needs to regulate the amount of hydrogen provided to the fuel cell stack (anode) to avoid starvation or waste of hydrogen [10]. In Figures 5 and 6, the resulting $\mathrm{F}_{\mathrm{H} 2}$ and $\mathrm{F}_{\mathrm{CO}}$ profiles at the output of stages 1,2 and 3 are plotted. We have excited the system by applying the disturbances represented in Figure 4.

Figure 5 shows hydrogen flows at the end of each one of the reforming process stages when disturbing the system as indicated in Figure 4. High magnitude instantaneous peaks occur because the increase of the volume flow at the entrance of the reactor results in an immediate increase in the flow at the reactor exit. For $\mathrm{F}_{\mathrm{C} 2 \mathrm{H} 5 \mathrm{OH}}$ and $\mathrm{T}_{\text {gas }}$ disturbances, this peak is an inverse response. After these peaks, with a slower dynamics, the new $\mathrm{F}_{\mathrm{H} 2}$ steady-state value is achieved. As expected, the time required to achieve the steady-state following variations in $\mathrm{F}_{\mathrm{C} 2 \mathrm{H} 5 \mathrm{OH}}, \mathrm{T}_{\text {gas }}$ and $\mathrm{F}_{\mathrm{H} 2 \mathrm{O}}$ is less than that 
following disturbances in $\mathrm{T}_{\mathrm{f}, \mathrm{S} 1}, \mathrm{~T}_{\mathrm{f}, \mathrm{S} 2}$ and $\mathrm{T}_{\mathrm{f}, \mathrm{S} 3}$. It is also relevant to notice that for $\mathrm{T}_{\mathrm{f}, \mathrm{S} 1}$ and $\mathrm{T}_{\mathrm{f}, \mathrm{S} 2}$, the time constant for positive changes is smaller than the time constant for negative changes. All these observations will be important at the controllers design stage. In Figure 6 the behaviour of $\mathrm{F}_{\mathrm{CO}}$ is shown, which is similar to that reported above for $\mathrm{F}_{\mathrm{H} 2}$. It is outstanding the influence of $\mathrm{T}_{\mathrm{f}, \mathrm{S} 2}$ at the exit of stage 2 .

\section{Steady-state sensitivity analysis}

In accordance to Figures 2 and 3, from a steady-state sensitivity analysis it is seen that an increase of $10 \%$ in $\mathrm{F}_{\mathrm{C} 2 \mathrm{H} 5 \mathrm{OH}}$ with respect to its nominal value originates an increase in $\mathrm{F}_{\mathrm{H} 2}$ and $\mathrm{F}_{\mathrm{CO}}$ at the outlet of stage 3 of $8 \%$ and $23 \%$, respectively. Therefore, it is not appropriate to increase $\mathrm{F}_{\mathrm{C} 2 \mathrm{H} 5 \mathrm{OH}}$ when more $\mathrm{F}_{\mathrm{H} 2}$ is required because larger quantities of $\mathrm{F}_{\mathrm{CO}}$ will be produced as well. On the other hand, an increase of $10 \%$ in $\mathrm{F}_{\mathrm{H} 2 \mathrm{O}}$ with respect to its nominal value produces a decrease in $\mathrm{F}_{\mathrm{H} 2}$ and $\mathrm{F}_{\mathrm{CO}}$ of $3 \%$ and $20 \%$, respectively. Therefore, it can be said that the sensitivity of $\mathrm{F}_{\mathrm{CO}}$ facing $\mathrm{F}_{\mathrm{C} 2 \mathrm{H} 5 \mathrm{OH}}$ and $\mathrm{F}_{\mathrm{H} 2 \mathrm{O}}$ changes is higher than the sensitivity of $\mathrm{F}_{\mathrm{H} 2}$.

Concerning the effect of temperature, when the furnace temperature in zone 1 is increased in $10 \%$, an increase in $\mathrm{F}_{\mathrm{H} 2}$ and $\mathrm{F}_{\mathrm{CO}}$ of $6 \%$ and $17 \%$, respectively, takes place. When the furnace temperature in zone 3 is increased in $10 \%$, an increase in $\mathrm{F}_{\mathrm{CO}}$ of $37 \%$ and a reduction in $\mathrm{F}_{\mathrm{H} 2}$ of $1.5 \%$ are observed. This is due to the water gas shift equilibrium, which yields $\mathrm{CO}$ at the expense of $\mathrm{H}_{2}$ at high temperatures. This input variable is then very important as control variable because of the sensitivity of the system to produce excess $\mathrm{CO}$ when this temperature is changed.

Because of the special behaviour caused by changes in the furnace temperature of stage 2 found in the previous analysis, the sensitivity of the system in front of this variable is carefully considered. With this aim we have plotted the steady state values of 
the outputs flowrates $\left(\mathrm{F}_{\mathrm{H} 2}\right.$ and $\left.\mathrm{F}_{\mathrm{CO}}\right)$ following changes in $\mathrm{T}_{\mathrm{f}, \mathrm{S} 2}$ with respect to the nominal operating point $\left(\mathrm{OP}_{\mathrm{n}}\right.$ in Table 2$)$.

In Figures 7 and 8 the hydrogen yield, $\eta^{\mathrm{H} 2}$, hydrogen molar flow rate, $\mathrm{F}_{\mathrm{H} 2}$, ethanol conversion, $\mathrm{x}_{\mathrm{C} 2 \mathrm{H} 5 \mathrm{OH}}$, and acetaldehyde conversion, $\mathrm{x}_{\mathrm{C} 2 \mathrm{H} 4 \mathrm{O}}$, are plotted at different $\mathrm{T}_{\mathrm{f}, \mathrm{S} 2}$ values. From Figure 7 it is seen that an increase of the furnace temperature in stage 2 originates a slight increase in $\mathrm{F}_{\mathrm{H} 2}$, whereas $\eta^{\mathrm{H} 2}$ increases with a higher rate. According to the reaction scheme, acetaldehyde conversion $\left(\mathrm{x}_{\mathrm{C} 2 \mathrm{H} 4 \mathrm{O}}\right)$ increases linearly with respect to temperature in stage 2 while the ethanol conversion $\left(\mathrm{x}_{\mathrm{C} 2 \mathrm{H} 5 \mathrm{OH}}\right)$ is kept constant (Figure 8). Figure 9 shows $\mathrm{F}_{\mathrm{CO}}$ at the outlet of stages 2 and 3. It can be seen that the influence of $\mathrm{T}_{\mathrm{f}, \mathrm{S} 2}$ over the $\mathrm{CO}$ production is very high.

\section{Controllability study}

In this section, a controllability analysis is performed using the Relative Gain Array (RGA), Condition Number (CN) and Morari Resiliency Index (MRI).

One of the most common approaches to control a multiple-input multiple-output (MIMO) system is to use a diagonal controller, which is often referred to as a decentralized controller. The decentralized control works well if the system is close to diagonal, which means that the plant can be considered as a collection of individual single-input single-output (SISO) subsystems that do not interact and can be considered independently. If an off-diagonal element is large, then the performance of the decentralized controller may be poor [2]. The controllability analysis based on RGA, $\mathrm{CN}$ and MRI permits to compare and select the control variables that minimise the interactions between crossed inputs and outputs.

\subsection{Relative gain array (RGA)}


The Relative Gain Array is an analytical tool used to determine the optimal control structure of a MIMO system. The RGA is a normalized form of the gain matrix that describes the interactions between inputs and outputs. Through the RGA, the process interaction of open-loop and closed-loop control systems is measured for all possible input-output variable pairings. A ratio between open-loop gains to closed-loop gains are determined and the results are displayed in the RGA matrix. From the RGA analysis, different rules can be derived for the selection of the appropriate control variables and the best pairings between the selected inputs and the controlled outputs [2]. Basically, RGA matrixes close to the identity matrix are preferred and control structures with high RGA elements should be avoided.

To perform the analysis of controllability of the reforming process, all possible combinations of two inputs among the six possible inputs have been considered (Table 4). The analysis is firstly done at zero frequency. At this frequency, pairs 1, 4, 8, 11 and 13 are the best because the values of $\operatorname{RGA}(1,1)$ are close to one. In contrast, pairs 6,7 and 9 can be discarded because they have negative elements in the RGA at steady state. We also eliminated pairs $2,3,5,10,12$ and 14 because with their high values in $\operatorname{RGA}(1,1)$, they would be very sensitive to input uncertainties.

\subsection{Condition number $(\mathrm{CN})$}

This index is the ratio between the maximum and minimum singular values of the gain matrix. High $\mathrm{CN}$ values indicate that it will be more difficult to control the process because of the sensitivity to uncertainties. For this reason we should select a set of inputs and outputs resulting in a system with small $\mathrm{CN}$. Looking at $\mathrm{CN}$ values compiled in table 4, pairs 1, 4, 8, 11 and 13 have the lower (preferred) values. 


\subsection{Morari resiliency index (MRI)}

The MRI (Morari Resilience Index) indicates whether a set of controlled variables and manipulated variables provides a simple control, giving a measure of the inherent controllability of the process: large values of MRI indicate that the process is more controllable. The pairs 1, 4, 8, 11 and 13 have also the higher MRI.

Having analysed the three controllability indexes at steady-state, it can be concluded that the control structures consisting in pairs $1,4,8,11$ and 13 are better than the other ones. For this reason, in the next section, only these structures will be considered.

\section{Selection of the control structures}

In this section, the steady state controllability analysis is completed with the analysis at different frequencies [2], and the best control structures are identified. Only pairs 1, 4, 8, 11 and 13 are taken into account. Pair 1 corresponds to of the manipulation of $\mathrm{F}_{\mathrm{C} 2 \mathrm{H} 5 \mathrm{OH}}$ for the control of $\mathrm{F}_{\mathrm{H} 2}$, and the manipulation of $\mathrm{F}_{\mathrm{H} 2 \mathrm{O}}$ for the control of $\mathrm{F}_{\mathrm{CO}}$. On the other hand, for the pairs $4,8,11$ and 13 if we need to control the $\mathrm{F}_{\mathrm{H} 2}$ we should act on $\mathrm{F}_{\mathrm{C} 2 \mathrm{H} 5 \mathrm{OH}}, \mathrm{F}_{\mathrm{H} 2 \mathrm{O}}, \mathrm{T}_{\mathrm{g}, \text { in }}$ and $\mathrm{T}_{\mathrm{f}, \mathrm{S} 1}$, respectively. To control the $\mathrm{F}_{\mathrm{CO}}$ we must act on the $\mathrm{T}_{\mathrm{f}, \mathrm{S} 2}$.

\subsection{Controllability frequential analysis}

The frequential analysis is done considering the frequency range from $10^{-3}$ to $10^{2} \mathrm{rad}$ $\mathrm{s}^{-1}$. In Figures 10-12 the results obtained for the different controllability indexes are shown. In the three figures, the order of the different pairs is maintained during a wide frequency range. The peaks observed in the three figures are due to numerical problems and occur at different frequencies if the system model is trunked with a different 
number of states. Pairs 4, 11 and 13 are the best in accordance to the three controllability indexes. Their RGA(1,1) and MRI (close to one) and CN (lower than 10) are acceptable values for scaled systems. In the three cases, to control the $\mathrm{F}_{\mathrm{CO}}$ the preferred manipulated variable is $\mathrm{T}_{\mathrm{f}, \mathrm{S} 2}$.

\section{CONCLUSIONS}

This work focuses on the design of controllers for an ethanol steam reformer, which is a MIMO system with six inputs and two controlled outputs. The main tasks of the work are the characterisation of the dynamic response and the selection of the preferred control structures. Both tasks are preliminary studies for the design of controllers. The dynamic response is analysed through a non-linear model. Inverse responses and nonlinearities are observed. The controllability analysis is based on a linear model. In accordance to RGA, MRI and CN controllability indexes, three different control structures are selected as the most promising ones for the control of $\mathrm{F}_{\mathrm{H} 2}$ and $\mathrm{F}_{\mathrm{CO}}$. They are the pairs consisting in the manipulation of $\mathrm{F}_{\mathrm{C} 2 \mathrm{H} 5 \mathrm{OH}}$ and $\mathrm{T}_{\mathrm{f}, \mathrm{S} 2}, \mathrm{~T}_{\mathrm{g} \text {,in }}$ and $\mathrm{T}_{\mathrm{f}, \mathrm{S} 2}$, and $\mathrm{T}_{\mathrm{f}, \mathrm{S} 1}$ and $\mathrm{T}_{\mathrm{f}, \mathrm{S} 2}$. All three pairs include the $\mathrm{T}_{\mathrm{f}, \mathrm{S} 2}$. These control structures are a priori appropriate for 2x2 MIMO decentralised control. However, due to the non-linearities of the system, specially apparent in the $\mathrm{T}_{\mathrm{f}, \mathrm{S} 2}$ response, the performance of the controllers cannot be confirmed until its validation in non-linear models.

\section{Acknowledgements}

This work has been funded through MICINN projects DPI2007-62966 and CTQ2009-12520. V.G. is grateful to Generalitat de Catalunya for a PhD fellowship. J.L. is grateful to ICREA Academia program. 


\section{Nomenclature}

C concentration $\left(\mathrm{mol} \mathrm{m}_{\mathrm{R}}{ }^{-3}\right)$

$c_{\mathrm{p}} \quad$ specific heat $\left(\mathrm{J} \mathrm{kg}^{-1} \mathrm{~K}^{-1}\right)$

$d_{t} \quad$ monolith external diameter $(m)$

F molar flowrate $\left(\mathrm{mol} \mathrm{s}^{-1}\right)$

$\mathrm{k}$ reaction rate constant $\left(\mathrm{mL} \mathrm{g}_{\text {cat }}{ }^{-1} \mathrm{~h}^{-1}\right)$

$\mathrm{K}$ equilibrium constant for homogeneous reaction

$\mathrm{t} \quad$ time $(\min )$

$\mathrm{T}$ temperature $(\mathrm{K})$

$\mathrm{T}_{\mathrm{F}} \quad$ furnace temperature $(\mathrm{K})$

$\mathrm{U}$ overall heat-transfer coefficient $\left(\mathrm{J} \mathrm{s}^{-1} \mathrm{~m}^{-2} \mathrm{k}^{-1}\right)$

y mole fraction

$\mathrm{p} \quad$ pressure $(\mathrm{atm})$

V superficial velocity $\left(\mathrm{m} \mathrm{s}^{-1}\right)$

$\mathrm{x}$ conversion

r velocity rate $\left(\mathrm{mol} \mathrm{m} \mathrm{R}^{-3} \mathrm{~s}^{-1}\right)$

$\eta^{\mathrm{H} 2}$ hydrogen yield (\%)

OP operating point

Subscripts

e equilibrium

in reactor input

out reactor output

gas gas 
i reaction number, $\mathrm{i}=1, \ldots, 3$ (ethanol decomposition, acetaldehyde reforming, water-gas shift, respectively)

j component number, $\mathrm{j}=1, \ldots, 6\left(\mathrm{C}_{2} \mathrm{H}_{5} \mathrm{OH}, \mathrm{H}_{2} \mathrm{O}, \mathrm{C}_{2} \mathrm{H}_{4} \mathrm{O}, \mathrm{H}_{2}, \mathrm{CO}, \mathrm{CO}_{2}\right.$, respectively)

$\mathrm{C} 2 \mathrm{H} 5 \mathrm{OH}$ relative to ethanol

$\mathrm{H} 2 \mathrm{O}$ relative to water

C2H4O relative to acetaldehyde

H2 relative to hydrogen

CO relative to carbon monoxide

O2 relative to oxygen

s solid

S1 $\quad$ stage 1

S2 $\quad$ stage 2

S3 $\quad$ stage 3

Greek letters

$\Delta \quad$ increment

$v_{\mathrm{ij}} \quad$ stoichiometric coefficient of component $\mathrm{j}$ in reaction $\mathrm{i}$

$\rho \quad$ density $\left(\mathrm{kg} \mathrm{m}^{-3}\right)$

\section{References}

[1] E.H. Bristol, IEEE Trans. on automatic control 55 (1966) 133-134.

[2] S. Skogestad, I. Postlethwaite, Multivariable Feedback Control, second ed., Wiley, England, 2005.

[3] V. García, E. López, M. Serra, J. Llorca, J Power Sources 192 (2009) 208-15.

[4] W. Poldolski, Y. Kim, Ind. Eng. Chem. 13 (1974) 415-421. 
[5] V. García, E. López, M. Serra, J. Llorca, J. Riera, Int. J. Hydrogen Energy 35 (2010) 9768-9775.

[6] E. Bissett, Se. Oh, R. Sinkevitch, Chem. Eng. Sci 60 (2005) 4709-4721.

[7] E. Bissett, Se. Oh, R. Sinkevitch, Chem. Eng. Sci. 60 (2005) 4722-4735.

[8] A. Cornelio, Indian Chem. Eng. 48 (2006) 164-174

[9] A. Casanovas, M. Saint-Gerons, F. Griffon, J. Llorca, Int. J. Hydrogen Energy 33 (2008) 1827-1833.

[10] D. Megede, J. Power Source 106 (2002) 35-41.

\section{Figures}

Figure 1: Reforming and purification process of an ethanol-water mixture.

Figure 2: Molar flow of hydrogen over time under incremental inputs in $\mathrm{F}_{\mathrm{C} 2 \mathrm{H} 5 \mathrm{OH} \text {,in, }}$ $\mathrm{F}_{\mathrm{H} 2 \mathrm{O}, \text { in }}, \mathrm{T}_{\mathrm{g}, \text { in }}$ and $\mathrm{T}_{\mathrm{f}, \mathrm{S} 2}$.

Figure 3: Molar flow of carbon monoxide over time under incremental inputs in $\mathrm{F}_{\mathrm{C} 2 \mathrm{H} 5 \mathrm{OH}, \mathrm{in}}, \mathrm{F}_{\mathrm{H} 2 \mathrm{O}, \text { in }}, \mathrm{T}_{\mathrm{g}, \text { in }}$ and $\mathrm{T}_{\mathrm{f}, \mathrm{S} 2}$.

Figure 4: Disturbances of the system, based on OPn nominal conditions (see Table 2)

Figure 5: Molar flow of hydrogen following the disturbances indicated in Fig 5.

Figure 6: Molar flow of carbon monoxide following the disturbances indicated in Fig 5.

Figure 7: Molar flow (solid lines) and yield of hydrogen (dotted lines) at different stage 2 furnace temperature values.

Figure 8: Ethanol conversion (solid lines) and acetaldehyde conversion (dotted lines) at different stage 2 furnace temperature values.

Figure 9: Molar flow of $\mathrm{CO}$ as function of the incremental input $\Delta \mathrm{T}_{\mathrm{f}, \mathrm{s} 3}$ in the outlet of stages 2 and 3.

Figure 10: Relative gain array RGA $(1,1)$ of different pairs.

Figure 11: Morari resiliency index (MRI) of different pairs.

Figure 12: Condition number $(\mathrm{CN})$ of different pairs. 